estimated from the matrix of IQ correlations involving biological mothers, their adopted-away offspring, adoptive parents, and the natural children of the adoptive parents.

Dr. Joseph M. Horn, Psychology-Department, University of Texas, Austin, Texas 7812 , USA

TWINS: COGNITIVE PATTERNING AND DEVELOPMENT AS MEASURED ON THE WEGHSLER PRESCHOOL AND PRIMARY SCALE OF INTELLIGENCE

\section{RONALD S. WILSON}

Louisville Twin Study, School of Medicine, University of Lotrisville, Kentucky, USA

Cognitive patterning and development was appraised for 142 pairs of twins at 4,5 , and 6 years of age, based on their test scores on the WPPSI. Compared with singletons, the twins showed an initial lag at age 4 , with V-IQ more depressed than P-IQ, but by age 6 the deficit was fully recovered. $\mathrm{MZ}$ twins displayed high within-pair correlations for V-IQ and P-IQ at age 4 , and the correlations further increased by age 6 as the measures of IQ became stabilized. $\mathrm{MZ}$ twins also showed significant concordance for the patterning of subtest scores. DZ twins displayed moderate within-pair correlations for IQ which declined somewhat over age, and which fell significantly below the MZ correlations. Measures of family socioeconomic status and parental education correlated $0.28-0.32$ with the twins' IQ at age 6 . The results indicated that within a broad range of home environments, the genotype exercised a profound influence on childhood mental development. It was coded not only for a general factor, as represented in Full Scale IQ, but also for the differential strength of the composite abilities which were separately measured on the Verbal and Performance Scales. In addition, the genotype was coded for the patterning of relative strengths and weaknesses as revealed on the individual subtests.

Ronald S. Wilson, Ph.D., Medical-Dental Research Bldg., Rm. I I H, P.O. Box 1055, Louisville, Kentucky 40201, USA
TWINS: CONCORDANCE IN INFANT DEVELOPMENT

AS MEASURED ON PIAGET-TYPE SGALE

ADAM P. MATHENY, JR., ANNE B. DOLAN, RONALD S. WILSON

Louisville Twin Study, School of Medicine, University of Louisville, Kentucky, USA

Bayley's Mental Scale was examined to determine which items were comparable to those found on Piagetian-type instruments used to assess infant development. Fifty items were found appropriate for infants during the first year of testing (at $3,6,9$, and I 2 months), and Io items were found for the second year of testing (at I8 and 24 months). Test data based on infant twins' responses to Bayley's Mental Scale were reanalyzed to determine if genetic influences could be found for infants' responses to a Piagetian-type scale. Within-pair correlations were obtained for I 26 same-sex twin pairs (82 MZ, $44 \mathrm{DZ}$ ) during the first year, and 154 same-sex twin pairs ( 9 I MZ, $63 \mathrm{DZ}$ ) during the second year. During the first year, the within-pair correlations for $\mathrm{MZ}$ and $\mathrm{DZ}$ twins were 0.83 and 0.55 , respectively; during the second year, the correlations were 0.66 and 0.40 . Despite the restriction in range of scores, especially during the second year, the data indicate that there are genetic influences on infant behavior assessed by Piagetian-type items analogous to those found for conventional infant mental tests.

Ronald S. Wilson, Ph.D., Medical-Dental Research Bldg., Rm. I1 IH, P.O. Box ı55, Louisville, Kentucky 40201, USA

\section{PSYGHOLOGICAL FOLLOW-UP STUDY IN TWINS FROM BIRTH TO FIVE YEARS}

W. DE COSTER, J. LEROU, G. DUTOIT, M DE ZUTTER, R. DEROM, M. THIERY

Departments of Psychology and of Obstetrics, State University, Ghent, Belgium

Classical psychological twin studies, planned as investigations of the respective influence of nature and nurture, have yielded 